\title{
Prevalence of Glucose Intolerance in Women with Poly- cystic Ovary Syndrome: Experience from a Tertiary Care Hospital
}

\author{
Laila $\mathrm{R}^{\mathrm{a}}$, Mahmud $\mathrm{N}^{\mathrm{b}}$, Nargis $\mathrm{M}^{\mathrm{c}}$, Chowdhury TA ${ }^{\mathrm{d}}$
}

\begin{abstract}
Background: Polycystic ovary syndrome (PCOS) is a common endocrine disorder affecting 5-10\% women of reproductive age. The prevalence of abnormal glucose tolerance (impaired fasting glucose, IFG, impaired glucose tolerance, IGT and type 2 diabetes mellitus, T2DM) in women with PCOS is substantially higher than expected when compared with age and weight-matched population of women without PCOS. The present study was conducted among women of reproductive age with PCOS to characterize the extent and nature of glucose intolerance.

Methods: This observational study was conducted in Centre for Assisted Reproduction (CARE), Department of Obstetrics and Gynaecology and Biomedical Research group, BIRDEM from January 2006 to December 2008.

Results: Total number of patients was 103 and their age ranged between 15 and 36 years. Fifty percent of them were overweight or obese. IGT and T2DM were present in $29.1 \%$ and $4.9 \%$ cases respectively. Body mass index (BMI) of patients with T2DM with PCOS was significantly higher than normal glucose tolerance (NGT) group $(p=0.005)$. There was no difference of BMI between NGT, with IGT and IGT with T2DM with PCOS. Diabetic PCOS women were older than NGT and IGT group ( $p=0.002, p=0.009$ respectively). Family history of diabetes was present in $80 \%$ diabetes PCOS compared to $63.3 \%$ in IGT and $39.7 \%$ of NGT with PCOS.

Conclusions: PCOS women have significantly increased prevalence of IGT and T2DM. Obesity and age substantially increase risk of glucose intolerance but IGT and T2DM can develop independent of obesity in PCOS women.
\end{abstract}

Key Words: impaired glucose tolerance; obesity; polycystic ovary syndrome; type 2 diabetes mellitus.

Birdem Med J 2016; 6(1): 36-39

\section{Introduction}

Polycystic ovary syndrome (PCOS) is a common endocrine disorder affecting 5-10\% women of reproductive age. ${ }^{1}$ The most widely accepted diagnostic

\section{Author Informations}

a. Dr. Rona Laila, MS, Resident Surgeon and Assistant Professor, Department of Gynae and Obstetrics, BIRDEM General Hospital 2.

b. Dr. Nusrat Mahmud, Consultant, Centre for Assisted Reproduction (CARE), BIRDEM General Hospital 2.

c. Dr. Monnujan Nargis, Research Officer, Research Division, BIRDEM.

d. Prof. TA Chowdhury, Professor and Chief Consultant, Department of Gynae and Obstetrics, BIRDEM General Hospital 2.

Address of correspondence: Dr. Rona Laila, MS, Resident Surgeon and Assistant Professor, Department of Gynae and Obstetrics, BIRDEM General Hospital 2. Email: ronalaila7776 @ gmail.com

Received: June 4, 2015 criteria is given by the National Institutes of Health (NIH) in 1990 defining it as hyperandrogenism and chronic anovulation in cases where secondary causes (such as adult onset congenital adrenal hyperplasia, hyperprolactinema and androgen secreting neoplasm) have been excluded. ${ }^{2}$

Though the majority of women with PCOS have basal hyperinsulinemia, studies that carefully assessed â cell function have discovered important defect in insulin secretion. ${ }^{3-5}$ In these women, incremental insulin secretory responses to meal are markedly reduced. ${ }^{3}$ Impairment of â cell function to respond to oscillation in plasma glucose and insulin secretory dysfunction in PCOS contributed significantly in the development of glucose intolerance. ${ }^{5}$ Insulin resistance and pancreatic $\beta$ cell dysfunction are both implicated in the pathophysiology of glucose intolerance. ${ }^{6}$ Obesity, 
particularly upper body obesity, is common among women with PCOS and it is well known that obesity increases the risk of glucose intolerance. ${ }^{7}$

Impaired glucose intolerance (IGT) and type 2 diabetes mellitus (T2DM) in women with PCOS varies between $31-35 \%$ and $7.5-10 \%$ respectively. ${ }^{8} 9$ Although IGT and diabetes were detected in non-obese and/or young PCOS women, the prevalence of both significantly increase with body mass index (BMI). ${ }^{8}$ Increased age substantially increases risk of IGT or diabetes. ${ }^{9}$ The conversion from IGT to T2DM is accelerated, perhaps as much as 5 to 10 fold in PCOS. ${ }^{8}$ The increased prevalence of abnormal glucose tolerance is not a universal feature. Ciampelli et al. reported that IGT is present only in obese hyperinsulinemic PCOS women with prevalence of $15.5 \%$ and none is affected by T2DM. ${ }^{10}$

Apart from the issue of BMI, the disagreement regarding the extent and nature of abnormal glucose tolerance may be due to the presence of racial heterogenecity, known to be present regarding glucose metabolism. Thus, it is important to investigate this issue in different populations. Since environmental factors and lifestyles play a key role in the development of glucose intolerance, it becomes additionally important to conduct such study in various ethnic groups. The present study has been undertaken in the above context to characterize glucose intolerance in a group of Bangladeshi PCOS women.

\section{Methods}

\section{Study subjects}

This observational study was conducted in Centre for Assisted Reproduction (CARE), Department of Obstetrics and Gynaecology and Biomedical Research Group, Bangladesh Institute of Research and Rehabilitation in Diabetes, Endocrine and Metabolic Disorders (BIRDEM) from January 2006 to December 2008. A total of 103 women with PCOS and of reproductive age group were included in this study.

PCOS was diagnosed by oligomenorrhea (menstrual cycle interval $>35$ days but $<6$ months duration) or amenorrhea (if no menstruation for 6 months or more), altered FSH to LH ratio (2:1) and one or more of the following criteria: subfertility, obesity, hirsutism, cystic acne, ultrasound evidence of bilateral enlarged ovaries with multiple (10 or more) small subcortical follicles (2$10 \mathrm{~mm}$ in diameter). Patients with PCOS along with known diabetes and other endrocrinopathy (e.g. hyperadrenalism, hypothyroidism) were excluded from the study.

\section{Methodology}

A detailed history (personal, family, medical) was taken and findings were noted in predesigned case record form. The body weight $(\mathrm{kg})$ was measured on light clothes and height $(\mathrm{cm})$ by using appropriate scales on bare foot (Detect-Medic, Detect Scales INC,USA). BMI was calculated using standard formula. Details anthropometry was measured by standard method.

Oral glucose tolerance test (OGTT) was performed in all subjects following the world health organization (WHO) criteria (1999). ${ }^{11}$ The selected subjects were requested to fast overnight (8-12 hours). On the following morning, fasting blood samples $(2 \mathrm{ml})$ was collected in a tube. After two hours of glucose load (75 gm), another $2 \mathrm{ml}$ blood was drawn in another tube.

The results were expressed as mean \pm standard deviation (SD) and median (range). Students unpaired t test, MannWhitney $\mathrm{U}$ test and $\mathrm{X}^{2}$ were used for data analysis. Pvalue of $<0.05$ was considered as significant. All statistical analyses were performed with the Statistical Package for Social Science (SPSS) software for Windows version 11.5 (SPSS Inc, Chicago, IL, USA).

\section{Results}

\section{Clinical Characteristics of the study subjects}

Total patients were 103 and their age ranged from 15 to 36 years. Base-line and anthropometric characteristics and clinical manifestations are presented in Table I.

Table I. Clinical characteristics of the study subjects $(\mathrm{N}=103)$

\begin{tabular}{lc} 
Parameter & PCOS $(\mathrm{n}=103)$ \\
\hline Age $($ years $)$ & $24.4 \pm 5.18$ \\
Height $(\mathrm{m})$ & $1.57 \pm 0.087$ \\
Weight $(\mathrm{kg})$ & $61(30-103)$ \\
BMI $\left(\mathrm{kg} / \mathrm{m}^{2}\right)$ & $25.84 \pm 5.54$ \\
Waist $(\mathrm{cm})$ & $90.05 \pm 13.94$ \\
Hip $(\mathrm{cm})$ & $97.09 \pm 11.79$ \\
Waist hip ratio & $0.93 \pm 0.13$ \\
Typical physical characteristics & $94(91.33 \%)$ \\
Positive family history of diabetes & $50(48.5 \%)$ \\
\hline
\end{tabular}

Results are expressed as mean $\pm \mathrm{SD}$, median (range) or No (\%) as appropriate 


\section{Frequency distribution of PCOS subjects according to glucose tolerance}

Among the study subjects, 30 (29.1\%) had IGT, 5(4.9\%) had T2DM and 68 (66\%) had normal glucose tolerance (NGT).

\section{Clinical characteristics of different groups of PCOS}

Detailed anthropometry and other clinical characteristics of different groups of PCOS are presented in Table II. Results are expressed as mean $\pm \mathrm{SD}$ and median (range) as appropriate. It was seen that patients with T2DM were older than patients with NGT and IGT and the difference was statistically significant (Table II). BMI of T2DM patients was also significantly higher than NGT $(p=0.005)$. Triceps of IGT was significantly higher than $\operatorname{NGT}(\mathrm{p}=0.009)$.

Table II. Clinical characteristics of different groups of PCOS

\begin{tabular}{|c|c|c|c|}
\hline Parameter & $\operatorname{NGT}(\mathrm{n}=68)$ & $\operatorname{IGT}(n=30)$ & $\mathrm{T} 2 \mathrm{DM}(\mathrm{n}=5)$ \\
\hline Age (years) & $23.68 \pm 4.57$ & $25.03 \pm 6.09$ & $30.40 \pm 2.88$ \\
\hline $\operatorname{BMI}\left(\mathrm{kg} / \mathrm{m}^{2}\right)$ & $24.86 \pm 5.70$ & $26.92 \pm 4.17$ & $32.70 \pm 7.56$ \\
\hline Triceps(mm) & $26.14 \pm 4.81$ & $29.29 \pm 6.47$ & $29.28 \pm 6.93$ \\
\hline Waist hip ratio & о $0.93 \pm 0.13$ & $0.94 \pm 0.14$ & $0.91 \pm 0.092$ \\
\hline Typical & $63(92.6 \%)$ & $27(90 \%)$ & $4(80 \%)$ \\
\hline \multicolumn{4}{|l|}{ Physical } \\
\hline \multicolumn{4}{|l|}{ Characteristics } \\
\hline \multirow{2}{*}{\multicolumn{2}{|c|}{$\begin{array}{l}\text { Positive family } 27(39.7 \%) \\
\text { history of } \\
\text { diabetes }\end{array}$}} & $19(63.3 \%)$ & $4(80 \%)$ \\
\hline & & & \\
\hline \multicolumn{4}{|l|}{ p value } \\
\hline & NGT & NGT & IGT \\
\hline & vs. IGT & vs. T2DM & vs. T2DM \\
\hline Age (years) & 0.281 & $0.002 *$ & 0.009 \\
\hline BMI (kg/m2) & 0.079 & $0.005^{*}$ & 0.164 \\
\hline Triceps (mm) & 0.009 & 0.177 & 0.998 \\
\hline Waist hip ratio & 0.640 & 0.812 & 0.672 \\
\hline
\end{tabular}

Results are expressed as mean $\pm \mathrm{SD}$, median (range) or No (\%) as appropriate; difference between groups was calculated using unpaired students t test and MannWhitney $U$ test where appropriate and *p value $<0.05$ is considered statistically significant

\section{Discussion}

In the present study on 103 PCOS women, $29.1 \%$ had IGT and $4.9 \%$ had T2DM. Legro et al. studied the prevalence of IGT and T2DM in two groups of PCOS (one in urban ethnically mixed group and another is rural ethnically homogeneous group) in USA and found $31.1 \%$ IGT and $7.5 \%$ T2DM in all PCOS subjects. ${ }^{8}$ Ehrmann et al. also studied on prevalence of IGT and DM in PCOS (mixed ethnic) women in Chicago and reported that $35 \%$ of PCOS had IGT and $10 \%$ had T2DM. ${ }^{9}$ Another study showed the prevalence of IGT in PCOS women is $30 \%-50 \%$ and that of T2DM is $5 \%-10 \% .{ }^{15} \mathrm{In}$ addition the conversion from IGT to T2DM was increased. ${ }^{15}$ Our data on IGT is almost comparable with their findings. However, there was a difference regarding the prevalence of T2DM, which was higher in their population. This may be due to presence of higher BMI of PCOS subjects in their studies. In Ehrmann's study BMI of non-insulin dependent DM (NIDDM) PCOS was $41.0 \pm 2.4 \mathrm{Kg} / \mathrm{m}^{2}$ and in Legro's study BMI of PCOS subjects was $29.9 \pm 8.1 \mathrm{Kg} / \mathrm{m}^{2}$ (in one group) and $35.9 \pm 8.0$ $\mathrm{Kg} / \mathrm{m}^{2}$ (in another group) whereas BMI of our PCOS subjects was $25.84 \pm 5.64 \mathrm{Kg} / \mathrm{m}^{2}$ and T2DM PCOS was $32.7 \pm 7.56 \mathrm{Kg} / \mathrm{m}^{2}$. It is clearly seen that BMI of our study subjects (both PCOS and T2DM PCOS) was much lower than Ehrmann and Legro's study.

The prevalence of IGT (29.1\%) was substantially higher in PCOS women than those found in a population based study by Sayeed et al. in a Bangladeshi population. ${ }^{12}$ They found that $8 \%$ of Bangladeshi population had IGT and 5.2\% had DM. Though the PCOS women are young (15-36 years) in comparison to Sayeed's study (30-60 years) still the prevalence of IGT in PCOS is much higher and if age was matched to 30-60 years it could be expected to be much higher. Although prevalence of $\operatorname{T} 2 \mathrm{DM}(4.9 \%)$ is similar to Sayeed et al.(5.2\%), yet, again if we consider age group then a prevalence of $4.9 \%$ is considerably high in this age group. Another two studies reported the prevalence of IGT is $15.7 \%$ \& $17.4 \%$ and $\mathrm{T} 2 \mathrm{DM}$ is $2.5 \%$ \& $4.3 \%$. The rate was higher in women with PCOS than expected in general population of similar age. ${ }^{16,17}$ Therefore, we can say that PCOS creates high risk population for developing IGT and T2DM.

It has been suggested that family history of diabetes worsens insulin secretion and glucose tolerance in PCOS women. ${ }^{13}$ We observed that $80 \%$ of DM and $63.3 \%$ of IGT with PCOS had family history of DM, whereas 39\% of NGT with PCOS had family history of DM. So, PCOS women with family history of DM are at greater risk for developing IGT and subsequently T2DM. Thus, there 
is a strong genetic component in the etiopathogenesis of PCOS and it needs to be explored.

Fifty percent PCOS women are usually obese. ${ }^{14}$ In our study, we also observed about $50 \%$ of PCOS had BMI $>25 \mathrm{Kg} / \mathrm{m}^{2}{ }^{2}$ We also observed that diabetic PCOS women were significantly more obese than those with NGT ( $\mathrm{p}=0.005)$. Obesity acts as an additional factor for developing DM in PCOS. ${ }^{8,9}$ In our study we found that there was no difference of BMI between IGT and NGT. Therefore, we can say that PCOS may be an independent factor for developing of IGT and BMI seems to be an additional factor for worsening glucose intolerance in PCOS.

\section{Conclusions}

PCOS women have significantly increased prevalence of IGT and T2DM. Obesity and increasing age substantially increase risk of glucose intolerance, but IGT and T2DM can develop independent to obesity in PCOS women. It may be recommended all women with PCOS have done OGTT at diagnosis. Regular follow-up can be useful in both long-term clinical management and encouraging patient lifestyle modification.

\section{Conflict of Interest: None.}

\section{References}

1. Knochenhauer ES, Key TJ, Kahsar-Miller M, Waggoner W, Boots LR, Azziz R. Prevalence of the polycystic ovary syndrome in unselected black and white women of the south-eastern United States: a perspective study. J Clin Endocr Metab 1999; 83: 3078-82.

2. Zawadzki J, Dunaif A. Diagnostic criteria for polycystic ovary syndrome: towards a rational approach. In: Dunaif A, Givens JR, Haseltimer FP, Merriam GR Editors. Polycystic ovary syndrome. Current issues in endocrinology and metabolism. $1^{\text {st }}$ ed. Boston (MA): Blackwell Scientific Publications. 1992; pp.377-384.

3. Omeara M, Blackman GD, Ehrmann DA, Barnes RB, Jaspan JB, Rosenfield RL, et al. B-cell function in functional ovarian hyperandrogenism. J Clin Endocrinol Metab 1993; 76: 1241-47.

4. Dunaif A, Finegood DT. B-cell dysfunction independent of obesity and glucose intolerance in the polycystic ovary syndrome. J Clin Endocrinol Metab 1996;81:942-47.

5. Eharmann DA, Sturis J, Byrne MM, Karrison T, Rosenfield $\mathrm{R}$, Polorsky K. Insulin secretory defect in PCOS: relationship to insulin sensitivity and family history of NIDDM. J Clin Invest 1995;96:520-22.

6. Lillioja S, Mott D, Sparul M. Insulin resistance and insulin secretory dysfunction as precursor of NIDDM. N Engl J Med 1993;1988-92.

7. Dunaif A, Givens J, Haseltine Fl. Upper body obesity, abnormalities in the metabolic profile and the androgen/ oestrogenic balance in PCOS. Blackwell Science 1992; pp.359-374.

8. Legro RS, Richard S, Allen R, Kunselman AR, Dodson WC. Prevalence and predictor of risk for type 2 diabetes mellitus and impaired glucose tolerance in polycystic ovary syndrome: a prospective controlled study in 254 affected women. J Clin Endocrinol Metab 1999; 84: 16569.

9. Ehrmann DA, Barnes RB, Rosenefield RL, Cavaghan MK, Imperial J. Prevalence of IGT and diabetes in women with PCOS. Diabetes Care 1999; 22:141-46.

10. Ciampelli M, Maria AF, Cucinelli F, Pavone V, Ronsisvalle E, Guido M, et al. Impact of insulin and BMI on metabolic endocrine variables in PCOS. Metab 1999;48:167-72.

11. World Health Organization 1999. Report of WHO consultation; definition, diagnosis and classification of diabetes mellitus and its complications. Part-I, Geneva.

12. Sayeed MA, Hossain ME, Banu A, Ali L, Hussain MZ, Rumi MAK, et al. Effect of socioeconomic risk factor on difference between rural and urban in the prevalence of diabetes in Bangladesh. Diabetes Care 1997;20:551-55.

13. Ehrmann DA, Legro RS, Azziz R, Ghazzi MN. A family history of type 2 diabetes predicts insulin resistance and glucose intolerance in PCOS. Program and abstracts of Endo 2001; 83 ${ }^{\text {rd }}$ Annual Meeting of the Endocrine Society; June 20-23, 2001; Denver, Colorado, Abstract P2-445.

14. Dunaif A, Segal KR, Shelley DR, Green G, Gobrjansky A, Licholai T. Evidence for distinctive and intrinsic defects in insulin action in polycystic ovary syndrome. Diabetes 1992;41:1257-66.

15. Legro RS, Gnatuk CL, Kunselman AR, Dunaif A. Changes in glucose tolerance over time in women with polycystic ovary syndrome: a controlled study. J Clin Endocrinol Metab 2005; 90: 3236-42.

16. Gambineri A, Pelusi C, Manicardi E, Vicennati V, CacciariM et al. Glucose Intolerance in a Large Cohort of Mediterranean Women With Polycystic Ovary Syndrome: Phenotype and Associated Factors. Diabetes 2004; 53: 2353-58.

17. Ünlühýzarcý K, Çolak R, Sahin Y, Bayram F, Kele ${ }^{\circ}$ timur F. The Prevalence of Glucose Intolerance in Women with Polycystic Ovary Syndrome.Turkish JEndocrinolMetab 2000; 4:135-37. 